\title{
BEYOND OAIS: TOWARDS A RELIABLE AND CONSISTENT DIGITAL PRESERVATION IMPLEMENTATION FRAMEWORK
}

\author{
Dennis Nicholson ${ }^{1}$, Milena Dobreva ${ }^{1,2}$ \\ ${ }^{1}$ Centre for Digital Library Research, Information Resources Directorate, University of Strathclyde \\ Livingstone Tower, 26 Richmond Street Glasgow, G1 1XH, United Kingdom \\ \{milena.dobreva|d.m.nicholson\}@strath.ac.uk \\ ${ }^{2}$ Institute of Mathematics and Informatics, bl. 8 Acad. G. Bonchev St., 1113 Sofia, Bulgaria
}

\begin{abstract}
Current work in digital preservation (DP) is dominated by the "Open Archival Information System" (OAIS) reference framework specified by the international standard ISO 14721:2003. This is a useful aid to understanding the concepts, main functional components and the basic data flows within a DP system, but does not give specific guidance on implementation-level issues. In this paper we suggest that there is a need for a reference architecture which goes beyond OAIS to address such implementationlevel issues - to specify minimum requirements in respect of the policies, processes, and metadata required to measure and validate repository trustworthiness in respect of the authenticity, integrity, renderability, meaning, and retrievability of the digital materials preserved. The suggestion is not that a particular way of implementing OAIS be specified, but, rather that general guidelines on implementation are required if the term "OAIS-compliant" is to be meaningful in the sense of giving an assurance of attaining and maintaining an operationally adequate or better level of long-term reliability, consistency, and crosscompatibility in implemented DP systems that is measurable, verifiable, manageable, and (as far as possible) futureproofed.
\end{abstract}

Index Terms - digital preservation, functional entities, data model, integrity, authenticity

\section{INTRODUCTION}

Over the last decade, in response to an increasing need for the introduction of common practices in assuring long term preservation of digital objects, the International Standards Organisation (ISO) developed a number of conceptual digital preservation (DP) standards and also some technical guidelines. The most commonly used standard in the area is ISO 14721:2003 (Space data and information transfer systems - Open archival information system - Reference model), widely known as OAIS [16]. It is a conceptual framework which presents the main functional components and identifies the basic data flows within a DP system.

OAIS provides a useful overview of the general concepts in the DP domain and their inter-relationships - as well as identifying, labelling, describing and detailing the scope of its various functional elements - and is a useful tool at this general level. It is currently undergoing a review which should only strengthen its ability to provide a good ongoing underlying basis for a next generation digital preservation framework at the general level that is its focus.

However, adequacy at this general level is not enough to ensure long-term reliability, consistency, and crosscompatibility of implemented DP systems. There are many ways of implementing a general standard like OAIS. This, by definition, means that OAIS is not enough in itself to ensure the successful preservation of digital materials. This will only be assured if OAIS is implemented in such a way as to ensure that the various OAIS functions are carried out reliably and consistently, both in the present and in the long term future (an essential requirement of successful DP). This, in turn, requires the provision of a DP framework that extends beyond OAIS itself to address a range of issues associated with the reliable and consistent long-term implementation of the standard. Creating a reference architecture that would provide such a framework is not a trivial task, and we can do no more than scratch the surface of the problem in this paper. It is made more difficult because the various professional communities which work on DP models and tools currently pursue a number of divergent approaches and their understanding of underlying DP principles is not always the same. For example the ISO/TR 18492:2005(E) Long-term Preservation of Electronic Document-based Information [7] was driven, as was OAIS, by a lack of harmony in respect of international guidance on the long-term preservation of electronic information. Its aim was "to provide a clear framework for strategy development and best practices that can be applied to a broad range of public and private sector electronic 
document-based information to ensure its long-term accessibility and authenticity", and was designed to help storage repositories of digital objects in developing their DP strategies. Six key issues that storage repositories need to address in the development of a long-term preservation strategy are identified:

- Readable electronic document-based information.

- Intelligible electronic document-based information.

- Identifiable electronic document-based information.

- Retrievable document-based information.

- Understandable document-based information.

- Authentic electronic document-based information.

These six issues are listed and elucidated in section 5 of the Technical Report [7], but formal definitions and metrics which would help to formalize the process of their application in practice are not offered there.

ISO/TR 18492:2005(E) also suggests the following three "primary activities that collectively form the foundation of any long-term preservation strategy":

a) Media renewal (which addresses media durability).

b) Document-based information migration (which addresses technological obsolescence).

c) Emulation of legacy information systems (which addresses the case of legacy information systems where no automated migration tools exist). However, it is stated that "up to this point it has encountered operational resistance for the purpose of long-term access to authentic electronic document-based information" [7], p. 7.

ISO/TR 18492:2005(E) offers a different perspective compared to OAIS general framework and suggests the elements needed to create a DP strategy addressing the case of electronic documents. Another point of view is suggested by ISO 15489-1:2001(E) Information and Documentation Records Management [6] - which looks at the complete digital object life-cycle management especially in the case of records. It defines records as "information created, received and maintained as evidence and information by an organization or person, in pursuance of legal obligations or in the transaction of business" and record management as the "field of management responsible for the efficient and systematic control of the creation, receipt, maintenance, use and disposition of records, including processes for capturing and maintaining evidence of and information about business activities and transactions in the form of records".

Section 7 in ISO 15489:1:2001 (E) outlines the key characteristics of a record: authenticity, reliability, integrity, and usability. Subsequently, in section 8 it introduces record systems characteristics: reliability, integrity, compliance to business requirements, comprehensiveness and systematic record management. The concept of a complete life cycle and its management which also suggests essential qualities enhances the understanding of DP.

However, even this very concise introduction to ISO work on DP-related standards illustrates that the foundations of the DP field are not uniformly seen and agreed upon in the professional community. Even the key issues in the DP domain are different: [7] talks about readability, intelligibility, identifiability, retrievability, understandability and authenticity, while [6] differentiates between the key characteristics of a record: authenticity, reliability, integrity, and usability and record systems characteristics: reliability, integrity, compliance to business requirements, comprehensiveness and systematic record management. In short, the international standards address different digital objects (records - documents - bitstreams), and also define different essential properties of the objects and the information system where these objects are stored and used.

One consequence of this is that current implementation work is characterised by varying levels of quality partly because there are no generally accepted implementation benchmarks in the DP community.

How can these, and other shortcomings, be overcome? What is necessary in order to offer an implementation framework which will guarantee a reliable DP system implementation and measurable results? We try to get closer to an answer to this question in what follows. We start with a presentation of the basic OAIS concepts in section 2. Then section 3 outlines the three major areas of current development of OAIS and examines the current understanding of "OAIS compliance". This is used to justify the claim that there is a need to introduce an implementation-oriented reference architecture aligned to the OAIS-driven top-down perspective. In section 4 we take three practical examples of the concepts of authenticity, integrity and chain of custody as an illustration of the need to add clear guidance in the reference architecture also taking a bottom-up perspective. Section 5 offers some concluding remarks.

\section{THE BASIC OAIS CONCEPTS}

The development of OAIS arose from the need for a functional model which would specify the basic components of a system for long-term preservation of digital objects and their relationships with the 'external world'. Brian Lavoie [11] offers an excellent introductory guide to OAIS where he describes the genesis of the model, the development of which was coordinated by the Consultative Committee for Space Data Systems $\left(\mathrm{CCSDS}^{1}\right)$ at the request of the ISO.

In Fig. 1, an OAIS is represented as a black box which is connected to other entities from the environment. These are Producers, Consumers, and Management. They are defined as follows: "Producer is the role played by those persons, or client systems, which provide the information to be preserved. Management is the role played by those who set overall OAIS policy as one component in a broader policy domain. Consumer is the role played by those persons, or client systems, that interact with OAIS services

\footnotetext{
${ }^{1}$ http://public.ccsds.org/default.aspx
} 
to find and acquire preserved information of interest. A special class of Consumers is the Designated Community. The Designated Community is the set of Consumers who should be able to understand the preserved information", see [16], p. 2.2-2.3.

It should be noted that these three roles - producer, consumer and management - are external to the archive. OAIS does not specify any roles within the archive itself; it defines functional entities but does not specify how they should be implemented if a system is to be OAIS compliant and - just as important - technically interoperable with other OAIS compliant systems.

The OAIS (archive) 'black box' is specified in more detail as a set of six functional entities. In addition to the definition of these functional entities, an OAIS information model explains the data flows between the environment and the archive, and also within the functional components of the archive.

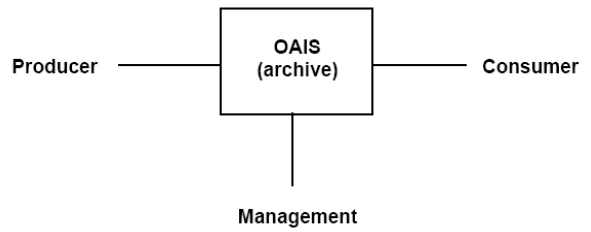

Fig. 1. Environment model of an OAIS, source p.2.2 [16]

Every act of submission of information to an OAIS by a Producer, as well as the dissemination of information to a Consumer, occurs either as a single discrete transmission, or as a series of transmissions. To describe the exchange of data, OAIS defines the concept of an Information Package as a "container" of two types of information: Content Information (CI) and Preservation Description Information (PDI). The Content Information and PDI are viewed as being encapsulated and identifiable by the Packaging Information (PI). OAIS defines three specialised types of information packages (IP), namely:

- Archival Information Package (AIP): An Information Package, consisting of the Content Information and the associated PDI, which is preserved within an OAIS.

- Dissemination Information Package (DIP): The Information Package, derived from one or more AIPs, received by the Consumer in response to a request to the OAIS.

- Submission Information Package (SIP): An Information Package that is delivered by the Producer to the OAIS for use in the construction of one or more AIPs.

PDI is divided into four types of preservation information called Provenance, Context, Reference, and Fixity. Provenance describes the source of the Content Information; Context describes how the Content Information relates to other information outside the Information Package.
Reference provides identifiers, by which the CI may be uniquely identified. Fixity provides a wrapper, which protects the CI from undocumented alteration.

A first key point to note is that OAIS does not suggest any specific metadata instantiations of PDI; so that there is no guidance on what constitutes a minimum technical requirement in respect of representing and encoding PDI information within corresponding PDI data bitstreams. There is also no guidance on the essential properties of the digital objects which need to be represented in the PDI. The definition of a minimum required set of data should be based on a study of what is required to assure a reliable, consistent, and measurable specification and implementation of a preservation system including the technical nature of the objects that it is processing.

A further level of granularity within OAIS is achieved through the introduction of six basic functional entities and their components. A diagram illustrating the functional entities of OAIS is presented on Fig. 2 and explained in Table 1.

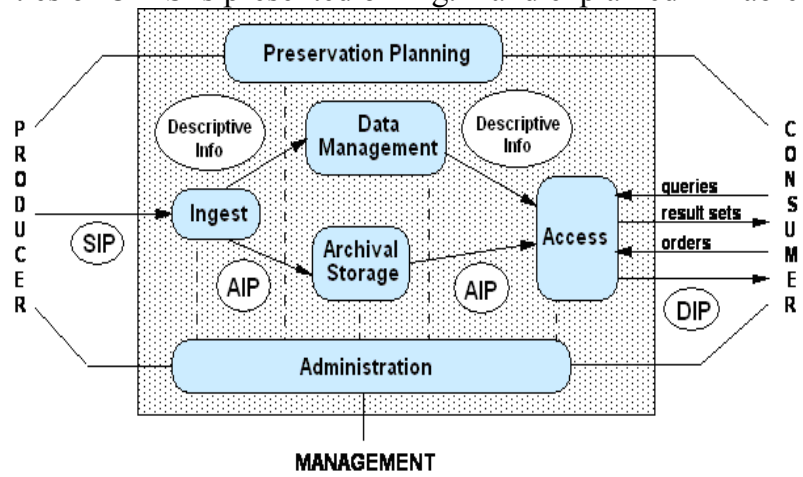

Fig. 2. The OAIS functional entities, source p.4-1, [16]

In addition to the functional entities described above, it is suggested that a number of basic Common Services are available, such as operation system services, network services, and security services. They are not shown in Fig 2. but are included in the OAIS model. Despite their general nature, such common services need to be studied in greater detail because they are strongly connected with the integrity and authenticity of digital objects which are essential for a reliable archive.

A second key point to note at this point is that OAIS does not specify or even conceptually suggest any specific interfaces and protocols to support design and implementation of its functional entities responsible for bitstream encoding during ingest, additional encoding during archival and preservation as well as adaptation and decoding during access. In consequence, there is no guidance on what constitutes a minimum technical requirement with respect to integrating functional bit stream processing into corresponding system designs which would help in the reallife implementations of DP systems.

Table 1. The functional entities in OAIS 


\begin{tabular}{|c|c|}
\hline $\begin{array}{c}\text { Functional entity and } \\
\text { description }\end{array}$ & $\begin{array}{c}\text { Functions which are implemented } \\
\text { within this entity }\end{array}$ \\
\hline $\begin{array}{l}\text { Ingest provides the services } \\
\text { and functions to accept SIPs } \\
\text { from Producers (or from } \\
\text { internal elements under } \\
\text { Administration control) and } \\
\text { prepare the contents for } \\
\text { storage and management } \\
\text { within the archive. }\end{array}$ & $\begin{array}{l}\text { Receiving SIPs, performing quality } \\
\text { assurance on SIPs, generating an AIP } \\
\text { which complies with the archive's data } \\
\text { formatting and documentation standards, } \\
\text { extracting Descriptive Information from } \\
\text { the SIPs for inclusion in the archive } \\
\text { database, and coordinating updates to } \\
\text { Archival Storage and Data Management. }\end{array}$ \\
\hline $\begin{array}{l}\text { Archival Storage provides } \\
\text { the services and functions } \\
\text { for the storage, maintenance } \\
\text { and retrieval of AIPs. }\end{array}$ & $\begin{array}{l}\text { Receiving AIPs from Ingest and adding } \\
\text { them to permanent storage, managing the } \\
\text { storage hierarchy, refreshing the media on } \\
\text { which archive holdings are stored, } \\
\text { performing routine and special error } \\
\text { checking, providing disaster recovery } \\
\text { capabilities, and providing AIPs to Access. }\end{array}$ \\
\hline $\begin{array}{l}\text { Data Management provides } \\
\text { the services and functions } \\
\text { for populating, maintaining, } \\
\text { and accessing both PDI } \\
\text { which identifies and } \\
\text { documents archive holdings } \\
\text { and administrative data used } \\
\text { to manage the archive. }\end{array}$ & $\begin{array}{l}\text { Administering the archive database } \\
\text { functions (maintaining schema and view } \\
\text { definitions, and referential integrity), } \\
\text { performing database updates (loading new } \\
\text { descriptive information or archive } \\
\text { administrative data), performing queries } \\
\text { on the data management data to generate } \\
\text { result sets, and producing reports from } \\
\text { these result sets. }\end{array}$ \\
\hline $\begin{array}{l}\text { Administration provides } \\
\text { the services and functions } \\
\text { for the overall operation of } \\
\text { the archive system. }\end{array}$ & $\begin{array}{l}\text { Soliciting and negotiating submission } \\
\text { agreements with Producers, auditing } \\
\text { submissions to ensure that they meet } \\
\text { archive standards, and maintaining } \\
\text { configuration management of system } \\
\text { hardware and software. System } \\
\text { engineering functions to monitor and } \\
\text { improve archive operations, and to } \\
\text { inventory, report on, and migrate/update } \\
\text { the contents of the archive. Also } \\
\text { establishes and maintains archive } \\
\text { standards and policies, providing customer } \\
\text { support, and activating stored requests. }\end{array}$ \\
\hline $\begin{array}{l}\text { Preservation Planning } \\
\text { provides the services and } \\
\text { functions for monitoring the } \\
\text { environment of the OAIS } \\
\text { and providing } \\
\text { recommendations to ensure } \\
\text { that the information stored } \\
\text { in the OAIS remains even if } \\
\text { the original computing } \\
\text { environment becomes } \\
\text { obsolete. }\end{array}$ & $\begin{array}{l}\text { Evaluating the contents of the archive and } \\
\text { periodically recommending archival } \\
\text { information updates to migrate current } \\
\text { archive holdings, developing } \\
\text { recommendations for archive standards } \\
\text { and policies, and monitoring changes in } \\
\text { the technology environment and in the } \\
\text { Designated Community's service } \\
\text { requirements and Knowledge Base. Also } \\
\text { designs IP templates and provides design } \\
\text { assistance and review to specialize these } \\
\text { templates into SIPs and AIPs for specific } \\
\text { submissions. Preservation Planning also } \\
\text { develops detailed Migration plans, } \\
\text { software prototypes and test plans to } \\
\text { enable implementation of Administration } \\
\text { migration goals. }\end{array}$ \\
\hline $\begin{array}{l}\text { Access provides the services } \\
\text { and functions that support } \\
\text { Consumers in determining } \\
\text { the existence, description, } \\
\text { location and availability of } \\
\text { information stored in the } \\
\text { OAIS, and allowing } \\
\text { Consumers to request and } \\
\text { receive information } \\
\text { products. }\end{array}$ & $\begin{array}{l}\text { Communicating with Consumers to } \\
\text { receive requests, applying controls to limit } \\
\text { access to specially protected information, } \\
\text { coordinating the execution of requests to } \\
\text { successful completion, generating } \\
\text { responses (DIPs, result sets, reports) and } \\
\text { delivering the responses to Consumers. }\end{array}$ \\
\hline
\end{tabular}

The definition of a minimum required set of interface functions and protocols should be based on a study of what is required to assure a reliable, consistent, and measurable specification and implementation of a preservation system including the technical nature of the functional entities and their implementations.

\section{THE WAY FORWARD: OAIS REVIEW AND COMPLAINCE TO OAIS}

\subsection{OAIS Five-Year Review}

OAIS is currently undergoing its five-year review. It is difficult to foresee what of the suggested revisions during the consultation process would be applied by the ISO and not all received suggestions for changes had been made public. However, The Digital Curation Centre made its suggestions public (see [3], p. 3), so it is possible to comment on these. The DCC document provides a number of useful clarifications and suggestions. For the purposes of our analysis, DCC Suggestion 10 is especially relevant: "Interaction with internal and external systems and services: OAIS seems to imply an 'insular' stand-alone archive but in reality it is likely to be part of a bigger organisation or network." This suggestion reinforces the need for more clarity with regard to the processes and information flows related to production (pre-Ingest) and re-use (post-Access).

Pre-ingest issues are taken up in DCC suggestion 12 (see [3], p. 4), which states that "Section $3^{2}$ could helpfully provide some additional information concerning the first stages of the ingest process, and explicitly reference the Producer-archive interface - Methodology abstract standard (ISO 20652:2006) and Information and documentation - Records management (ISO 15489: 2001)" - see [6] and [14] and "Any "producer-archive interface model" of early ingest would have to relate to ISO 15489." (see [6]).

This suggestion highlights two issues: the first one is the identified need for more detailed knowledge on the preingest stage which in essence means closer integration between work on the archive and the work of the producers. The second is to reach a higher level of understanding of how the digital preservation process fits into the current models of the life-cycle management of digital objects (and in particular to the ISO 15489 standard).

The post-production stage also needs to be examined in more detail. One area which seems not to be sufficiently developed is re-use of material stored in an archive. Some studies shed light on the re-use of materials in specific subject domains (see e.g. [2], a report on the long-term retention and re-use of e-learning objects and the article [20] on long-term reuse in the library context).

DCC recommendations were amongst the responses which the ISO received during the consultation process which informed the 5-year review of OAIS. ISO received

\footnotetext{
${ }^{2}$ The section numbers is taken from the OAIS standard [16].
} 
multiple comments and suggestions from different sources. They informed the creation of a revised version of OAIS. At the time of the preparation of this deliverable, ISO is still collecting feedback from the originators. Based on the feedback, a new version of the OAIS standard should be prepared for publication in January 2009.

Before this process of OAIS review is completed we cannot comment on the revisions. However, there are two areas of suggested changes we would like to mention specifically.

1. The revisions include definitions of the concepts of authenticity and integrity and seek to define more clearly their place within the archival system.

2. The revisions cover the preservation planning functional entity in greater detail, compared to the current version of the OAIS.

The analysis of the publicly known suggested revisions shows that there are no major structural changes expected in the revised version of the OAIS which means that suggestions and conclusions made in this paper should not be in any disagreement with the OAIS philosophy even after the review. Also, there is no suggestion for further clarification of the roles within the archive, nor more detailed implementation guidance.

\subsection{OAIS Use in Repository Context}

Another useful set of recommendations on OAIS development, although not formally bound to the five-year review (but related to its use in the digital repositories context) were suggested in [1]:

- To adequately specify reference models for repositories further work is necessary and could include clarification or deeper analysis of some of the contentious areas plus activity to scope the 'middle layer', gathering existing information, developing a repository typology and ecology, analysis of the community and stakeholders and exploring the need for multiple contextualised models. Assessing the compliance of existing repositories could provide useful case studies.

- For the Information Model, metadata mappings and crosswalks, analysis of issues surrounding complex collections and content packaging and clarification of how repositories might generate and store the SIP, DIP and AIP, would be useful exercises.

These two suggestions illustrate that there is a perceived need for further specification and adaptation of OAIS at the implementation level. The focus in [1] is on digital repositories, but it should be clear that these are general issues for any implementation which aims to be OAIS-compatible.

\subsection{Three Major Areas of Further Development of} OAIS

Brian Lavoie in [11] identified two areas of activity related to OAIS requiring deeper consideration: metadata requirements associated with the long-term preservation of digital materials and attributes of a trusted digital repository. In addition to them, we add here as another key domain of development the PAIS (A Producer-Archive Interface Standard) which led to a new proposal for an international standard.

\subsubsection{PAIS (A Producer-Archive Interface Standard)}

PAIS [14] was developed as a recommendation identifying, defining and providing structure to the relationships and interactions between a Producer and an Archive. It identifies four phases in the process of transferring information, suggests actions which should be carried out during each phase, and provides a general framework which facilitates the identification and/or development of standards and software tools to be used within the ingest process. The four stages and basic outputs of PAIS are presented on Fig. 3.

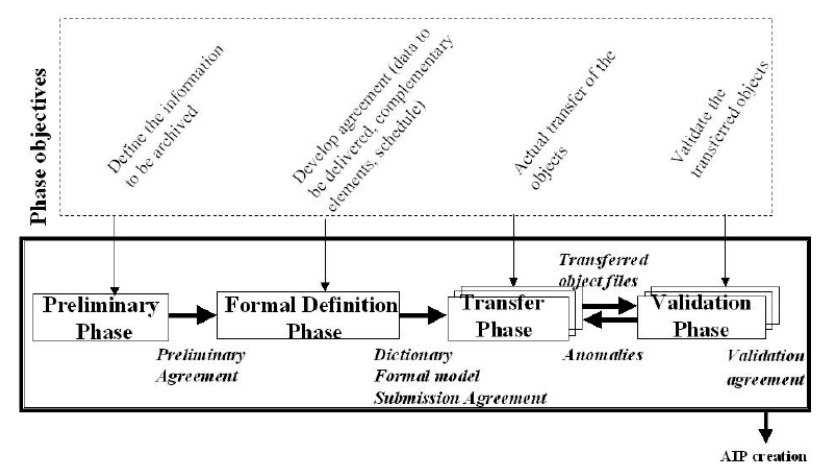

Fig. 3. PAIS: Main Phase Objectives and Outputs. See p. 2-5 [14]

Synthesizing the experience of Public Record Office of Northern Ireland (PRONI) Zoë Smyth suggested in [18] an even more detailed breakdown of the pre-ingest activities. The approach applied in PRONI foresees preliminary research on information needed for the archiving of records (including the topics of file formats, metadata, migration, appraisal and access), which precedes the four stages suggested in PAIS.

These examples illustrate the growing acknowledgement of the importance of the pre-ingest collaboration between the producer and the archive.

However, while implementation-level architecture remains unspecified, these areas will also be prone to multiple interpretations in respect of real-life implementations.

\subsubsection{Metadata Requirements Associated with the Long- term Preservation of Digital Materials}

In 2002 OCLC (Online Computer Library Center, Inc.) and RLG (Research Libraries Group) created a working group to explore how a consensus between different projects and initiatives in the field of preservation metadata could be achieved. This working group looked into the concepts within the OAIS model and analysed how metadata models 
could be applied in accordance with the OAIS information model. OAIS does not use the term metadata.

The white paper [10] surveys preservation metadata for digital objects within CEDARS $^{3}$ project, the National Library of Australia (NLA) Digital Preservation activities ${ }^{4}$ and the $\mathrm{NEDLIB}^{5}$ project. The white paper presents a comparative table which presents what elements in CEDARS, NLA and NEDLIB metadata represent PDI (reference information, context information, provenance information, fixity information) and content information.

The activities of the work group continued with the definition of metadata framework to support the preservation of digital objects (see [9]). According to this report, the work was "conducted for the purpose of developing an implementation of the information model $^{6}$ that would accommodate the needs of the library community, along with other institutions tasked with the long-term management of information in digital form." The same publication defines a body of recommended metadata for digital preservation, which is being developed in the coming years under the name PREMIS: PREservation Metadata Implementation Strategies (see [15]).

The effort which led to the development of PREMIS started with the clear intention to specify in more detail the metadata elements which would help the implementation of OAIS in practice, with a strong emphasis on the library domain.

The effort of OCLC and RLG to define preservation metadata is a major development in the DP field. However, it analyses only preservation metadata related to the digital object itself. A number of other issues likely to appear in real implementation scenarios are not considered, for example the preservation and re-use of descriptive and other metadata which might have been supplied with the digital object. Such metadata could be of help in generating preservation metadata, or could be later used for access (as defined conceptually in OAIS and technically in the Computer Science field of Information Retrieval, see Klas et al. [8]) and its various implementation strategies supporting information behaviours like searching, browsing etc.. The preservation and the development of search aids like indices or catalogues is out of the scope of PREMIS.

\subsubsection{Trusted Repositories and DP}

A third trend of OAIS-related work is the development of the concept of trusted digital repositories and it adaptation to the DP domain. This area brings us back to the essential qualities of the digital objects taken care of, and to the

\footnotetext{
${ }^{3} \mathrm{http}: / / \mathrm{www}$. leeds.ac.uk/cedars/

${ }^{4} \mathrm{http}: / /$ www.nla.gov.au/policy/digpres.html

${ }^{5}$ Metadata for Long Term Preservation / by C. Lupovici and J.

Masanès, BNF. Den Haag: KB, 2000. ISBN 90-62-59-1469

http://nedlib.kb.nl/results/NEDLIBmetadata.pdf.

${ }^{6}$ The information model of OAIS.
}

qualities of the DP system as a whole. Various professional communities and institutions develop checklists which should help to establish trustworthy digital preservation processes (see [13], [19]).

\subsection{OAIS Compliance}

Having a standard for long-term digital preservation systems had an essential impact on the development of a common professional understanding and vocabulary. It also had an impact on the subsequent development of related standards, such as PAIS [14], and as a guide to the setting up of preservation systems. Yet, the complexity of the area allows for multiple interpretations of how OAIS should be implemented in real life applications. This arguably gives rise to a need to develop generic guidelines to inform implementation and also to adjust any practical solution to policy frameworks.

Brian Lavoie in [11] notes that the term "OAIScompliant" is commonly used but is quite vague in its meaning. He also stresses that "the reference model is not an implementation: it says nothing about system architectures, storage or processing technologies, database design, computing platforms, or any of the myriad technical details involved in setting up a functioning archival system" (p 14).

Attempts have been made to formally define "OAIScompliance" in order to identify which implementations can claim it. J. Allison suggested the following three conformance criteria for OAIS-compliant repositories [1], p. 5:

A conforming OAIS archive shall fulfil the responsibilities listed in $3.1^{7}$, namely the OAIS must:

- Negotiate for and accept appropriate information from information Producers.

- Obtain sufficient control of the information provided to the level needed to ensure Long-Term Preservation.

- Determine which communities should become the Designated Community and, therefore, should be able to understand the information provided.

- Ensure that the information to be preserved is Independently Understandable to the Designated Community. In other words, the community should be able to understand the information without needing the assistance of the experts who produced the information.

- Follow documented policies and procedures which ensure that the information is preserved against all reasonable contingencies, and which enable the information to be disseminated as authenticated copies of the original, or as traceable to the original.

- Make the preserved information available to the Designated Community. ([16] p. 3-1)

\footnotetext{
${ }^{7}$ The numberings in the list of requirements are taken from [16].
} 
- A conforming OAIS archive implementation should be able to support the model of information described in 2.2 .

Standards or other documents that claim to be conformant to the OAIS Reference Model shall use the terms and concepts defined in the OAIS Reference Model in the same manner ([16] p. 1-3).

These points provide helpful initial guidance on OAIS compliance, but are still very high level, leaving much room for interpretation. Arguably, what is required is guidance at the level of functional entities - a minimum set of functions which an OAIS-compliant system should offer and associated indications of required levels of reliability and measurability. This will not e easy to achieve, but is, we believe a significant need.

\section{EXAMPLE: VARIOUS INTERPRETATIONS OF BASIC CONCEPTS IN DP}

One way to start building towards meeting the need in implementation-level architecture is to take a top-down approach following the functional and data models in OAIS aiming to identify the components which would provide unambiguous guidance to future developments. However, such an approach would only be successful if there was consensus on the basic concepts in DP. Our examples in the Introduction with key issues and properties in the standards [6] and [7] are showing that such a consensus is not in place. In Table 2 we take three basic concepts, authenticity, integrity and chain of custody, and offer definitions of those, accompanied by the rules and criteria in repository audit checklists, which mention these concepts.

A comparison of the various criteria demonstrates that the implied actions in respect of implemented preservations systems differ. This reflects associated differences in the perspectives taken on digital preservation policy level issues and related processes and their inter-relationships. In order to build interoperable solutions in the future, there should be a shared understanding and a minimum set of concepts which are commonly accepted by the DP professional community. This would include basic characteristics which need to be implemented as a minimum set of requirements in every preservation system.

Table 2. Some basic concepts and various views on them

\begin{tabular}{|c|c|}
\hline Definition & Rules in different repository audit systems \\
\hline \multicolumn{2}{|l|}{ Authenticity } \\
\hline $\begin{array}{l}\text { Authenticity is a key } \\
\text { preservation element which } \\
\text { asserts the provenance of a } \\
\text { digital object. It guarantees } \\
\text { that the object is stored } \\
\text { intact as it had been } \\
\text { created. }\end{array}$ & $\begin{array}{l}\text { TRAC B1.3: Repository has mechanisms } \\
\text { to authenticate the source of all materials. } \\
\text { nestor: B7. Repository ensures authenticity } \\
\text { of digital objects for all steps of processing } \\
\text { - Ingest } \\
\text { - Archival storage } \\
\text { - Access } \\
\text { ERA6.6. The system shall check the }\end{array}$ \\
\hline
\end{tabular}

\begin{tabular}{|c|c|}
\hline & $\begin{array}{l}\text { authenticity of sample electronic records. } \\
\text { ERA20.11. The system shall maintain the } \\
\text { authenticity of an electronic record during } \\
\text { access. }\end{array}$ \\
\hline \multicolumn{2}{|l|}{ Integrity } \\
\hline $\begin{array}{l}\text { "The quality of being } \\
\text { complete and unaltered in } \\
\text { all essential respects." [4], } \\
\text { p.24. } \\
\text { The quality of being whole } \\
\text { and unaltered through loss, } \\
\text { tampering, or corruption. } \\
\text { [17] }\end{array}$ & $\begin{array}{l}\text { TRAC: A3.8 Repository commits to } \\
\text { defining, collecting, tracking, and } \\
\text { providing, on demand, its information } \\
\text { integrity measurements. } \\
\text { B2.12 Repository provides an independent } \\
\text { mechanism for audit of the integrity of the } \\
\text { repository collection/content } \\
\text { nestor: B6 Repository ensures integrity of } \\
\text { digital objects for all steps of processing } \\
6.1 \text { Ingest } \\
6.2 \text { Archival storage } \\
6.3 \text { Access. } \\
\text { ERA8.1.6, The system shall preserve the } \\
\text { integrity of records throughout the } \\
\text { preservation processes }\end{array}$ \\
\hline \multicolumn{2}{|l|}{ Chain of custody } \\
\hline $\begin{array}{l}\text { Custody is defined as "The } \\
\text { physical and legal control } \\
\text { over the existence, } \\
\text { authenticity, location, and } \\
\text { accessibility of records." } \\
\text { [5], p.3. }\end{array}$ & $\begin{array}{l}\text { TRAC: A3.8 Repository commits to } \\
\text { defining, collecting, tracking, and } \\
\text { providing, on demand, its information } \\
\text { integrity measurements. (The chain of } \\
\text { custody for all of its digital content from the } \\
\text { point of deposit forward must be explicit, } \\
\text { complete, correct, and current). }\end{array}$ \\
\hline $\begin{array}{l}\text { The ability to demonstrate } \\
\text { an unbroken chain of } \\
\text { custody is an important test } \\
\text { of the authenticity of } \\
\text { records or evidence. [17] }\end{array}$ & $\begin{array}{l}\text { Nestor: n.a. } \\
\text { ERA1.3 The system shall provide the } \\
\text { capability to transfer legal custody of } \\
\text { records to NARA }\end{array}$ \\
\hline
\end{tabular}

An approach which suggests basing the implementation of DP systems on such lists of requirements is suggested in [12]. This is in a way a bottom-up approach, which integrates a specific policy in a DP system. In addition to such bottom-up policy implementation, the DP reference architecture would benefit from identifying the common base of concepts and reaching consensus on the essential properties of the DP systems.

The examples provided in Table 2 come from different high-level views on DP as expressed in repository audit systems; the combination of such requirements with a bottom-up approach as proposed in [12] would help to trace consistently the inner dependencies between concepts in the DP domain which currently are not interpreted in the same way by different policies. This is a huge task but it can help to map implementation of different presentation policies by specific DP systems.

\section{CONCLUSIONS}

In this paper we examined OAIS and its development and explained the need to define a generic implementation-level reference architecture. We suggested that this should be achieved through a combination of a top-down approach (which would be based on the OAIS reference architecture) 
with a bottom-up approach (which will crystallize an unambiguous common set of basic concepts and qualities in the DP domain).

Extensions required to support a next generation DP framework and underpin associated tools lie not at the level addressed by OAIS but in the area of specification and implementation. There are many ways of implementing a general standard like OAIS. This, by definition, means that OAIS is not enough in itself to ensure the successful preservation of digital materials. This will only be assured if OAIS is implemented in such a way as to ensure that the various OAIS functions are carried out reliably and consistently, both in the present and in the long term future (an essential requirement of successful DP). This, in turn, requires the provision of a DP framework that extends beyond OAIS itself to address a range of issues associated with the reliable, consistent, and measurable long-term implementation of the standard.

In addition, we showed that there are several areas which need to be better defined in the future, and in particular vis-à-vis the implementation level architecture. The DP professional community still can improve the knowledge on the roles within the archive. OAIS suggests three roles which represent the external environment of an archive (producer, consumer, and management), but the roles within the archive itself are not specified. A detailed understanding of these roles and the extent to which they could be reliably automated is necessary to clarify the notion of OAIS-compliance in implemented digital preservation systems. It is also necessary to cross-map OAIS with standards which deal with life-cycle management of digital objects. OAIS implementations may benefit from cross-fertilisation with the areas which are more advanced in life-cycle management of digital objects. Another need is to define better the details related to production (preIngest) and re-use (post-Access) possibly as separate functional entities. The current research identifies that these two components need to be clearly defined in order to guarantee proper integration of the preservation system in the broader information context.

Acknowledgement. This work was done within the EC-supported project SHAMAN.

\section{REFERENCES}

[1] Allinson, J. OAIS as a reference model for repositories: an evaluation (2006) Available:

http://www.ukoln.ac.uk/repositories/publications/oais-evaluation200607/Drs-OAIS-evaluation-0.5.pdf

[2] Barker, S., James, H., Knight, G., Milligan, C., Polfreman, M. LongTerm Retention and Reuse of E-Learning Objects and Materials, Report Commissioned by JISC. (2004)

[3] Higgins, S., Semple, N.. OAIS Five-year review: Recommendations for update, Compiled on behalf of members of The Digital Curation Centre and The Digital Preservation Coalition (2006) Available: http://www.dcc.ac.uk/docs/publications/OAIS_5-Year_Review.pdf
[4] InterPARES 2 Project glossary. 2008. Available: http://www.interpares.org/ip2/display_file.cfm?doc=ip2_glossary.pdf $\&$ CFID $=184179 \&$ CFTOKEN $=88579295$

[5] InterPARES glossary. 2001. Available: http://www.interpares.org/book/interpares_book_q_gloss.pdf

[6] ISO 15489-1:2001(E) Information and Documentation - Records Management - Part 1: General.

[7] ISO/TR 18492:2005(E) Long-term Preservation of Electronic Document-based Information. Technical report ISO/TR 18492. ISBN $0580478270,18 \mathrm{pp}$.

[8] Klas C.-P., Fuhr, N., Schaefer, A. Evaluating Strategic Support for Information Access in the DAFFODIL System. In: Research and Advanced Technology for Digital Libraries. Proc. European Conference on Digital Libraries (ECDL 2004), LNCS 3232, Springer, pp. 476-487. (2004) Available: http://www.springerlink.com/content/ba6wuqcygj634y42/

[9] Lavoie, B.F., ed. Preservation metadata and the OAIS information model: A metadata framework to support the preservation of digital objects (OCLC/RLG working group on preservation metadata). OCLC Research publication. (2002) Available: http://www.oclc.org/research/projects/pmwg/pm_framework.pdf

[10] Lavoie, B.F., ed. Preservation metadata for digital objects: A review of the state of the art (A white paper by the OCLC/RLG working group on preservation metadata). OCLC Research publication. (2001) Available:

http://www.oclc.org/research/projects/pmwg/presmeta_wp.pdf

[11] Lavoie, B. The Open Archival Information System Reference Model: Introductory Guide. DPC Technology Watch Report 04-01, 19 pp. (2004) Available: http://www.dpconline.org/docs/lavoie_OAIS.pdf

[12] Moore, R. \& Smith, M. (2007)

Automated Validation of Trusted Digital Repository Assessment Criteria, Journal of Digital Information 8(2). Available: http://journals.tdl.org/jodi/article/view/198/181

[13] nestor-Kriterien, Kriterienkatalog vertrauenswürdige digitale Langzeitarchive - Version 2 -. (2008) Available: http://edoc.huberlin.de/series/nestor-materialien/8/PDF/8.pdf

[14] PAIS: Recommendation for a Producer-Archive Interface Methodology Abstract Standard, CCSDS 651.0-B-1, BLUE BOOK, May 2004.

[15] PREMIS Data Dictionary for Preservation Metadata: PREMIS version 2.0, (2008) Available: http://www.loc.gov/standards/premis/v2/premis2-0.pdf

[16] Reference Model for an Open Archival Information System (OAIS) CCSDS 650.0-B-1 BLUE BOOK (2003) Available: http://public.ccsds.org/publications/archive/650x0b1.pdf

[17] SAA A glossary of archival and records terminology. 2005. Available: http://www.archivists.org/glossary/

[18] Smyth Z., Developing a pre-ingest strategy for digital records, Presentation at the Joint DCC/LUCAS Workshop, 30.11-1.12.2006, Foresight Centre, Liverpool (2006). Available: http://www.dcc.ac.uk/events/archives-2006/preingest.pps.

[19] Trustworthy Repositories Audit \& Certification (TRAC): Criteria and Checklist, RLG-NARA, v.1. Available: http://www.crl.edu/content.asp?11 $=13 \& 12=58 \& 13=162 \& 14=91$.

[20] van Wijngaarden, H. Long-term preservation and permanent access: How to ensure the long-term reuse value of your digital assets. Journal of Digit Asset Management, Vol. 3, pp. 102- 109, ISSN 1743-6540 (2007) Available: http://dx.doi.org/10.1057/palgrave.dam.3650064 